\title{
Needs for gerodontological treatment in the elderly living in Lower Silesia
}

\section{Gerostomatologiczne potrzeby lecznicze u dolnośląskich seniorów}

\author{
Beata Głowacka ${ }^{B-D, F}$, Tomasz Konopka ${ }^{A, C-F}$ \\ Department of Periodontology, Faculty of Dentistry, Wroclaw Medical University, Poland \\ A - research concept and design; $\mathrm{B}$ - collection and/or assembly of data; $\mathrm{C}$ - data analysis and interpretation; \\ $D$ - writing the article; $E$ - critical revision of the article; $F$ - final approval of the article
}

\begin{abstract}
Address for correspondence
Beata Głowacka
\end{abstract}

E-mail: beata.glowacka@umed.wroc.pl

Funding sources

None declared

Conflict of interest

None declared

Received on September 16, 2018

Reviewed on December 26, 2018

Accepted on January 22, 2019

Published online on March 29, 2019

Cite as

Głowacka B, Konopka T. Needs for gerodontological treatment in the elderly living in Lower Silesia. Dent Med Probl. 2019;56(1):89-96. doi:10.17219/dmp/103094

DOI

10.17219/dmp/103094

Copyright

๑ 2019 by Wroclaw Medical University

This is an article distributed under the terms of the

Creative Commons Attribution Non-Commercial License

(http://creativecommons.org/licenses/by-nc-nd/4.0/)

\begin{abstract}
Background. Many factors influence decisions regarding gerodontological treatment. Apart from the clinical condition of a patient, there is a complex of crucial socioeconomic factors, comorbidities, place of residence, and psychological aspects. Therefore, gerodontological treatment plans are significantly diversified.

Objectives. One of the goals of our cross-sectional epidemiological study of Lower Silesia seniors aged 65-74 was to identify all their needs related to gerodontological treatment.

Material and methods. From the randomly selected sample group of 1,600 people, 387 inhabitants of Wrocław and Oława reported to take part in the study. The anamnestic study identified demographic and socioeconomic determinants, coexistence of general diseases and behavioral variables related to oral health behaviors. In the clinical study, the decayed-missing-filled (DMF) index, the community periodontal index (CPI), oral hygiene indices, clinical pathological lesions in oral mucosa, and the index of prosthetic reconstruction of missing teeth according to the World Health Organization (WHO) were determined. Criteria for the need for prosthetic treatment, dental caries treatment, periodontal disease treatment, improvement of oral hygiene, and treatment of mucosal diseases, including potentially pre-cancerous and cancerous disorders, were defined.
\end{abstract}

Results. As many as $95.6 \%$ of all respondents required at least 1 form of dental treatment. The most common need (75\%) was prosthetic treatment of missing teeth either in the maxilla or in the mandible. Forty-nine percent of the respondents needed treatment of caries in the clinical crown or root of at least 1 tooth. Further, these needs were related to the following factors: treatment of oral mucosal diseases (35.4\%), professional periodontal treatment (35\%), improvement of very bad oral hygiene (29.2\%), and oncological treatment of pre-cancerous and cancerous lesions in the oral cavity (9.6\%).

Conclusions. The needs for gerodontological treatment found in the regional study of young Lower Silesian seniors are very high and cannot be met by services provided and funded by the state.

Key words: the elderly, oral health, treatment needs, dental treatment

Słowa kluczowe: osoby starsze, zdrowie jamy ustnej, potrzeby lecznicze, leczenie stomatologiczne 


\section{Introduction}

The elderly form a very heterogeneous group in terms of clinical dental status. There is an issue significant in their case, which is the accumulation of consequences of caries along with periodontopathies, which generates dental treatment needs. These usually include conservative treatment of natural dentition (including, in particular, root caries treatment), treatment of periodontal and oral mucosa diseases, as well as prosthetic treatment (most often of severe tooth loss and edentulism). The general schedule of gerodontological treatment should include ${ }^{1}$ : emergency care, maintenance and monitoring (treatment of carious lesions, non-surgical periodontal treatment, improvement of oral health behaviors, protection of abutment teeth, and reconstructive prosthetic treatment) and rehabilitation phase (surgical pre-prosthetic treatment, implantological treatment, prosthetic rehabilitation treatment, including the improvement of esthetics).

The possibilities of gerodontological treatment, as well as the expectations of these patients and their sense of need for treatment, and - in consequence - the scope of dental services, depend largely on the economic situation of the society. In developing countries, the treatment of oral cavity pathologies focuses on the control of pain, and the functional and esthetic rehabilitation of the masticatory system is not a priority. In societies with higher health awareness, comprehensive dental treatment aims to preserve or restore the function of the stomatognathic system to the highest possible level. Therefore, patients often expect an improvement of the esthetics of teeth, in connection with integrated gerodontological treatment.

A plan for such integrated treatment should take into account not only clinical indications, but also the expectations, general health and financial status of a patient. Many patients expect to undergo treatment solely refunded by the National Health Fund (NFZ). ${ }^{2}$ According to the assessment of the size and structure of public and non-public expenditure allocated to healthcare in Poland in 2009-2015, NFZ's expenditure on healthcare services in total increased by $17.7 \%$, while its expenditure on dental services decreased by $5.4 \%{ }^{3}$ As a result, the number of dental consultations and procedures in NFZ-financed facilities has dropped. According to the Statistics Poland, $70.9 \%$ of visits to a dentist are financed from patients' own funds. ${ }^{4}$ In 2013, the lack of sufficient financial resources was the reason for not using dental care services in the case of $30.7 \%$ of people with an income up to PLN 400 per family member and $9.5 \%$ of people earning an income above PLN 1,600 per family member. ${ }^{3}$ In 2016 , only $14.4 \%$ of outpatient dental consultations financed from public funds took the form of advice given to people over $65 .^{5}$

In Polish conditions, under the NFZ contract, both the conservative treatment of carious disease and its complications, as well as the non-surgical periodontal and prosthetic treatment with movable restorations are often the procedures of choice. However, this is not usually the most effective process and does not take into account many basic possibilities of modern dentistry. The inability to carry out many additional tests free of charge often makes it difficult to diagnose oral mucosa diseases and to choose the most appropriate method of periodontal treatment. The material status of a patient may be an obstacle to the comprehensive rehabilitation of the stomatognathic system. ${ }^{6}$

The needs of the elderly in the field of dental treatment are considerable. The profile of these needs is changing along with the prolongation of professional activity of older people, the increase in the importance of selfpresentation and their greater awareness of therapeutic possibilities offered by modern dentistry. Adequate orientation of the healthcare system in relation to oral health issues should be based on current epidemiological data.

One of the goals of this cross-sectional epidemiological study of the population of Lower Silesia inhabitants aged 65-74 was to identify the majority of needs regarding gerodontological treatment.

\section{Material and methods}

The methodology for selecting the study population aged 65-74 for a cross-sectional epidemiological study among the inhabitants of Wrocław and its surrounding area was presented in another paper. ${ }^{7}$ The research was conducted from June 25 to October 30, 2017, at the Department of Periodontology, Faculty of Dentistry of Wroclaw Medical University, and in a private specialist dental practice in Oława (Praktyka Prywatna, Dentyści Oława), Poland. The persons reporting to take part in the study signed written consent approved by the Bioethics Commission at Wroclaw Medical University (opinion No. KB$712 / 2017)$. In total, 387 people were examined (136 men and 149 women from Wrocław, and 50 men and 52 women from Oława). The response rate for research was $24.2 \%$ ( $28.5 \%$ for a large city and $17 \%$ for a small city).

The following information on variables was obtained in the interview:

- place of residence (Wrocław, Oława);

- age (based on PESEL number);

- gender;

- education (primary, secondary, higher);

- income per capita in the household (PLN 800 and below; PLN 801-2,500; PLN 2,500 and above);

- body weight and height, along with the body mass index (BMI) based on these measurements (proper weight $-\mathrm{BMI}<25 \mathrm{~kg} / \mathrm{m}^{2}$; overweight $-25 \leq \mathrm{BMI} \leq 30 \mathrm{~kg} / \mathrm{m}^{2}$; obesity - BMI > $30 \mathrm{~kg} / \mathrm{m}^{2}$ );

- general diseases: cardiovascular diseases (conditions without incident, e.g., coronary heart disease, cardiac arrhythmias or thrombotic diseases; and with a previous incident - myocardial infarction or stroke), diabetes, hypertension, osteoporosis (with the pharmacological 
treatment of the declared disease taken as the diagnostic criterion);

- nicotine addiction - in line with the WHO guidelines, ${ }^{8}$ the participants were classified as follows: non-smokers (people who had never smoked or had smoked fewer than 100 cigarettes throughout their lives); ex-smokers (people who used to smoke regularly, but had been free of addiction for at least a year at the time of the examination); and current smokers (people who had been smoking a minimum of 1 cigarette a day during the 6 months preceding the examination);

- oral health behaviors: average number of visits in a dental office during the previous 5 years (at least 2 visits per year were considered regular); the frequency of brushing natural teeth or prosthesis (brushing at least twice daily was considered regular); daily additional cleaning of the interdental spaces with dental floss or a special brush (yes/no);

- forms of dental treatment funding: only in state-financed facilities (NFZ); only in private facilities; or the mixed way.

The clinical examination was performed in LED lighting, with the use of a dental mirror and the PCPUNC 15 periodontal probe (Hu-Firedy Mfg Co., LLC, Chicago, USA).

The following parameters were determined during the examination:

- the number of preserved natural teeth, excluding third molars;

- the occurrence of tooth caries and its consequences, expressed numerically by the decayed-missing-filled tooth (DMFT) index and its components;

- the occurrence of plaque on the vestibular and lingual surfaces of the teeth, and the modified plaque control record (PCR) according to O'Leary et al. ${ }^{9}$;

- the occurrence of plaque in the interproximal spaces, and the approximal plaque index (API) according to Lange et al. ${ }^{10}$;

- the community periodontal index (CPI) codes, ${ }^{11} \mathrm{calcu}$ lated on the basis of a periodontal examination, including the assessment of pocket depth, gingival bleeding and the presence of calculus for each sextant (sextant I: teeth 17-14, II: teeth 13-23, III: teeth 24-27, IV: teeth 37-34, V: teeth 33-43, and VI: teeth 44-47); moreover, CPI was determined for the highest code value for each participant;

- the occurrence of clinical oral mucosal lesions, excluding congenital abnormalities or lesions not requiring treatment, e.g., dislocated sebaceous glands, linea alba or varicose veins of the tongue;

- the type and number of fixed and/or removable prosthetic restorations used; the condition and suitability of these prosthetic restorations were also assessed: the quality of the fixed restorations in the gingival area was evaluated, along with the reconstruction of occlusal points/planes, absence of interference with central and non-central occlusion, and absence of mechanical damage; with regard to the movable restorations, attention was paid to their adhesion to the prosthetic base, their retention and stabilization, as well as restored occlusion height (inappropriate or worn out restorations were counted as a prosthetic treatment need); a single missing tooth that would not cause a loss of occlusion point contacts in the dental arch and premature occlusion obstacles was not counted as an indication for prosthetic reconstruction;

- the need for prosthetic reconstruction of missing teeth according to the WHO classification ${ }^{12}$ was assessed separately for the maxilla and the mandible, and the following codes were assigned:

- 0 - no prosthetic treatment needed;

- 1 - the need for a single-unit prosthesis;

- 2 - the need for a multi-unit prosthesis;

- 3 - the need for a combination of a single- and/or multi-unit prosthesis;

- 4 - the need for prosthetic treatment of edentulism.

The following criteria conditioning the needs of dental treatment were adopted:

- cariological: visible clinical lesions, classified on the basis of the WHO clinical criteria ${ }^{13}$; caries lesions (without classification as clinical crown and root caries) at D3 irreversible stage (evident defect including the external part of dentin/cementum ${ }^{14}$ ) were registered as requiring treatment;

- periodontological: the criterion for the need for periodontal treatment was the one adopted in 1992 by the American Academy of Periodontology, namely the Periodontal Screening and Recording (PSR) index - more than 2 sextants with code 3 or 1 with code 4 in $\mathrm{CPI}^{15}$;

- oral hygiene: the absolute necessity to improve the effectiveness of tooth brushing and cleaning interdental spaces with the values of both periodontal index (PI) and API above 70\%;

- clinical oral mucosal pathology: the presence of at least 1 lesion requiring specialized treatment, e.g., prosthetic stomatitis, candidiasis, herpetic lesions, or burning mouth syndrome;

- pre-cancerous or cancerous: the presence of at least 1 potentially malignant disorder in the oral cavity (e.g., leukoplakia, lichen planus) or the presence of 1 benign/ malignant neoplastic lesion;

- prosthetic: the WHO value ${ }^{12}$ above 0 in the maxilla or in the mandible.

The hypothesis of equality of average parameters in 2 groups was verified with the Mann-Whitney test. The hypothesis of equality of average parameters in more than 2 groups was verified with the Kruskal-Wallis rank sum test (the homogeneity of variance was checked by the Levene test). For the parameters for which statistically significant differences were shown in the comparison of all 3 groups, multiple comparisons of mean ranks for all trials were carried out. For discrete parameters, the frequency of occurrences in the groups was analyzed by 
the $X^{2} d f$ test (sometimes the $X^{2}$ test with the Yates correction). For each test, $p<0.05$ was considered statistically significant. Statistical analysis was carried out using the Statistica software v.13.1 (StatSoft Polska, Kraków, Poland).

\section{Results}

In the entire study group with as many as 370 people, which constituted $95.6 \%$ of all the participants, required at least 1 form of dental treatment. The demand for the identified 6 main needs regarding gerodontological treatment, as well as the accepted criteria for needs are summarized in Table 1. The most common need concerned $75.5 \%$ indications for the prosthetic treatment of missing teeth defined on the basis of the WHO index for people with a code greater than 0 in the maxilla or in the mandible. The second need concerned $49.1 \%$ of the participants, requiring treatment of dental caries in the crown or root of at least 1 tooth. The average DMFT index for the entire study group was 17.8 and its components were as follows: decayed teeth (DT) 1.05; missing teeth (MT) (due to caries only) - 12.28; and filled teeth (FT) -4.48 . The third most frequently defined need was related to the indication for specialist periodontal treatment in $35 \%$ of the participants. The percentage of indications regarding the treatment of oral mucosa diseases (35.4\%) was quite similar. It included the need for treatment of such diseases as prosthetic stomatitis, angular cheilitis, leukokeratosis, candidiasis, herpes simplex, geographic tongue, burning mouth syndrome, xerostomia vera, recurrent aphthous stomatitis, and smoker's palate, and potentially malignant and neoplastic disorders. The latter group concerned as much as $9.6 \%$ of the subjects and included such diagnoses as: leukoplakia, lichen planus, pigmented lesions, as well as benign tumors (hemangiomas, fibromas, papillomas, and epulises) and 1 case of tongue cancer. The necessity to improve very bad oral hygiene was found in $29.2 \%$ of the respondents.

The need for prosthetic treatment in the maxilla occurred in $61 \%$ of the subjects, in the mandible - in $66.9 \%$. Regarding the maxilla, there was a significantly more frequent need for a multi-unit prosthesis (WHO code 2$)(p=0.023)$ and to restore prosthetically edentulism (WHO code 4$)(p=0.0046)$; regarding the mandible, there was a need to restore a combination of a single missing tooth and/or a multi-unit case (WHO code 3 ) $(p=0.0001)$ (Table 2$)$. With regard to the maxilla,

Table 2. The need for prosthetic reconstruction of missing teeth according to the WHO classification in the whole group

\begin{tabular}{|c|c|c|c|c|c|}
\hline \multirow{2}{*}{$\begin{array}{c}\text { WHO } \\
\text { classification }\end{array}$} & \multicolumn{2}{|c|}{ Maxilla } & \multicolumn{2}{|c|}{ Mandible } & \multirow[b]{2}{*}{$p$-value } \\
\hline & $\begin{array}{l}\text { number } \\
\text { of people }\end{array}$ & $\begin{array}{c}\text { percentage } \\
{[\%]}\end{array}$ & $\begin{array}{c}\text { number } \\
\text { of people }\end{array}$ & $\begin{array}{c}\text { percentage } \\
{[\%]}\end{array}$ & \\
\hline 0 & 151 & 39 & 128 & 33.1 & 0.085 \\
\hline 1 & 33 & 8.5 & 34 & 8.8 & 0.97 \\
\hline 2 & 18 & 4.7 & 6 & 1.4 & $0.023^{*}$ \\
\hline 3 & 119 & 30.7 & 180 & 46.5 & $0.0001^{*}$ \\
\hline 4 & 66 & 17.1 & 39 & 10.1 & $0.0046^{*}$ \\
\hline
\end{tabular}

* statistically significant.

Table 1. Dental treatment needs

\begin{tabular}{|c|c|c|c|}
\hline Treatment need & Criterion & $\begin{array}{c}\text { Percentage } \\
\text { in the whole group } \\
{[\%]}\end{array}$ & $\begin{array}{c}\text { Three subgroups* } \\
\text { with the highest treatment needs } \\
{[\%]}\end{array}$ \\
\hline Prosthetic treatment & $\begin{array}{l}\text { WHO code }>0 \\
\text { in the maxilla } \\
\text { or in the mandible }\end{array}$ & 75.5 & $\begin{array}{l}\text { irregular brushing }-83.3 \\
\text { male sex }-82.3 \\
\text { active smoking }-81.5\end{array}$ \\
\hline Dental caries treatment** & $\mathrm{DT} \geq 1$ & 49.1 & $\begin{array}{c}\text { lowest income }-77.7 \\
\text { primary education }-69.2 \\
\text { active smoking }-69.2\end{array}$ \\
\hline $\begin{array}{l}\text { Specialist periodontal } \\
\text { treatment }\end{array}$ & $\begin{array}{l}>2 \text { sextants with code } 3 \\
\text { or } 1 \text { sextant with code } 4 \\
\text { in CPI }\end{array}$ & 35 & $\begin{array}{c}\text { active smoking }-57.7 \\
\text { cardiovascular disease with incidence }-57.1 \\
\text { male sex }-40.9\end{array}$ \\
\hline $\begin{array}{l}\text { Necessity to improve } \\
\text { very bad oral hygiene }\end{array}$ & $\begin{array}{c}\mathrm{PI}>70 \% \\
\text { and } \mathrm{API}>70 \%\end{array}$ & 29.2 & $\begin{array}{l}\text { irregular brushing }-50.6 \\
\text { active smoking }-46.1 \\
\text { lowest income }-44.7\end{array}$ \\
\hline $\begin{array}{l}\text { Treatment of oral mucosa } \\
\text { diseases }\end{array}$ & $\begin{array}{c}\text { presence of at least } \\
1 \text { disease requiring treatment }\end{array}$ & 35.4 & $\begin{array}{l}\text { active smoking }-47.7 \\
\text { lowest income }-47.4 \\
\text { treatment funded by NFZ }-43.6\end{array}$ \\
\hline $\begin{array}{l}\text { Treatment of oral pre-cancerous } \\
\text { and cancerous lesions }\end{array}$ & $\begin{array}{l}\text { presence of at least } \\
1 \text { lesion }\end{array}$ & 9.6 & $\begin{array}{c}\text { active smoking }-15.4 \\
\text { female sex }-12.9 \\
\text { cardiovascular disease }-11.9\end{array}$ \\
\hline
\end{tabular}

API - approximal plaque index; CPI - community periodontal index; DT - decayed teeth; PI - periodontal index; WHO - World Health Organization; * 14 subgroups were tested: place of residence, sex, education, income per capita, smoking status (current or former), obesity, diabetes, presence of cardiovascular disease or a previous incident - myocardial infarction or stroke, hypertension, osteoporosis, irregularity of visits to the dental office, irregularity of tooth brushing, no flossing, and treatment only in state-funded facilities (NFZ); ${ }^{*}$ Edentulous people were excluded. 
the need for prosthetic treatment of more extensive tooth loss was found in people with primary education - as compared to persons with higher education $(p<0.0001)$, people treated in NFZ facilities - as compared to persons self-financing their dental treatment or only sometimes involving their own means $(p<0.0001)$, irregularly brushing teeth $(p<0.0001)$, ineffectively brushing teeth $(p=0.0002)$, having irregular dental visits $(p=0.0005)$, declaring tobacco addiction in the past - as compared to persons completely abstaining from smoking $(p=0.015)$, and living in a small town $(p=0.0298)$ (Table 3$)$. For the mandible, the need for prosthetic treatment of more extensive tooth loss depended significantly on a smaller number of conditions: inefficient tooth brushing $(p<0.0001)$, dental treatment funded by the state - as compared to self-financed treatment $(p<0.0001)$, irregular tooth brushing $(p=0.0002)$, primary education - as compared to higher education $(p=0.0009)$, and irregular dental visits $(p=0.0031)$ (Table 4$)$.

\section{Discussion}

In our study, according to the WHO classification, it was observed that $39 \%$ of the participants did not need any prosthetic restoration in the maxilla, and $33.1 \%$ - in the mandible. These findings were almost identical to those made in the analogous West Pomeranian study: 39.1\% in the maxilla and $32.3 \%$ in the mandible. ${ }^{16}$ However, this data was significantly worse than other European ones; for instance, the national Spanish study in 2005 showed that the absence of the said necessity for prosthetic treatment was determined in $76.3 \%$ of participants in the maxilla and $71.5 \%$ in the mandible, in people of the same age. ${ }^{17}$

In young Lower Silesian seniors, the need for prosthetic restoration of a single missing tooth or restorative prosthetic treatment in multi-unit or combined (single- and/or multi-unit) cases was found in $43.9 \%$ in the maxilla and $56.7 \%$ in the mandible; in the West Pomeranian group, these were $50.3 \%$ and $58.8 \%$, respectively. ${ }^{16}$

Table 3. The need for prosthetic treatment in the maxilla according to the WHO classification, depending on chosen variables

\begin{tabular}{|c|c|c|c|}
\hline \multicolumn{2}{|c|}{ Variable } & $\begin{array}{l}\text { Median value } \\
\text { of WHO codes }\end{array}$ & $p$-value \\
\hline Place of residence & $\begin{array}{l}\text { Wrocław } \\
\text { Oława }\end{array}$ & $\begin{array}{l}1(0-4) \\
3(0-4)\end{array}$ & $0.0298^{*}$ \\
\hline Sex & $\begin{array}{l}\text { female } \\
\text { male }\end{array}$ & $\begin{array}{l}1(0-4) \\
3(0-4)\end{array}$ & 0.0723 \\
\hline Education & $\begin{array}{l}\text { elementary }{ }^{1} \\
\text { secondary } \\
\text { higher }^{3}\end{array}$ & $\begin{array}{l}3(0-4) \\
2(0-4) \\
1(0-4)\end{array}$ & $\begin{array}{c}0.0001^{*} \\
\text { between }{ }^{1} \text { and }^{3} \\
<0.0001 \\
\text { between }{ }^{2} \text { and }^{3} \\
0.02\end{array}$ \\
\hline Income & $\begin{array}{l}\text { lowest } \\
\text { average } \\
\text { highest }\end{array}$ & $\begin{array}{l}3(0-4) \\
1(0-4) \\
2(0-4)\end{array}$ & 0.094 \\
\hline Smoking status & $\begin{array}{c}\text { current } \\
\text { former } \\
\text { non-smoker }{ }^{2}\end{array}$ & $\begin{array}{l}3(0-4) \\
3(0-4) \\
1(0-4)\end{array}$ & $\begin{array}{c}0.0062^{*} \\
\text { between }{ }^{1} \text { and }^{2} \\
0.015\end{array}$ \\
\hline BMI & $\begin{array}{l}\text { normal weight } \\
\text { overweight } \\
\text { obesity }\end{array}$ & $\begin{array}{l}1(0-4) \\
3(0-4) \\
1(0-4)\end{array}$ & 0.49 \\
\hline Diabetes & $\begin{array}{l}\text { yes } \\
\text { no }\end{array}$ & $\begin{array}{l}3(0-4) \\
2(0-4)\end{array}$ & 0.41 \\
\hline Cardiovascular disease & $\begin{array}{l}\text { yes } \\
\text { no }\end{array}$ & $\begin{array}{l}2(0-4) \\
2(0-4)\end{array}$ & 0.0913 \\
\hline Osteoporosis & $\begin{array}{l}\text { yes } \\
\text { no }\end{array}$ & $\begin{array}{l}0(0-4) \\
2(0-4)\end{array}$ & 0.0684 \\
\hline Effectiveness of tooth brushing & $\begin{array}{l}\mathrm{PI}<30 \% \\
\mathrm{PI}>70 \%\end{array}$ & $\begin{array}{l}0.5(0-4) \\
3(0-4)\end{array}$ & $0.0002^{*}$ \\
\hline $\begin{array}{l}\text { Effectiveness of hygienic procedures } \\
\text { in interdental spaces }\end{array}$ & $\begin{array}{l}\mathrm{API}<25 \% \\
\mathrm{API}>70 \%\end{array}$ & $\begin{array}{l}2.5(0-4) \\
3(0-4)\end{array}$ & 0.51 \\
\hline Dental appointments & $\begin{array}{l}\text { regularly } \\
\text { irregularly }\end{array}$ & $\begin{array}{l}1(0-4) \\
3(0-4)\end{array}$ & $0.0005^{*}$ \\
\hline Brushing teeth & $\begin{array}{l}\text { regularly } \\
\text { irregularly }\end{array}$ & $\begin{array}{l}1(0-4) \\
3(0-4)\end{array}$ & $0.0001^{*}$ \\
\hline Form of dental treatment funding & $\begin{array}{l}\text { NFZ1 } \\
\text { mixed } \\
\text { private }\end{array}$ & $\begin{array}{c}3(0-4) \\
1.5(0-4) \\
1(0-4)\end{array}$ & $\begin{array}{l}0.0001^{*} \\
\text { between } 1 \text { and the rest } \\
<0.0001\end{array}$ \\
\hline
\end{tabular}

BMI - body mass index; * statistically significant. 
Table 4. The need for prosthetic treatment in the mandible according to the WHO classification, depending on chosen variables

\begin{tabular}{|c|c|c|c|}
\hline \multicolumn{2}{|c|}{ Variable } & \multirow{2}{*}{$\begin{array}{l}\begin{array}{c}\text { Median value } \\
\text { of WHO codes }\end{array} \\
\begin{array}{c}3(0-4) \\
3(0-4)\end{array}\end{array}$} & \multirow{2}{*}{$\begin{array}{c}p \text {-value } \\
0.13\end{array}$} \\
\hline Place of residence & $\begin{array}{l}\text { Wrocław } \\
\text { Oława }\end{array}$ & & \\
\hline Sex & $\begin{array}{l}\text { female } \\
\text { male }\end{array}$ & $\begin{array}{l}3(0-4) \\
3(0-4)\end{array}$ & 0.16 \\
\hline Education & $\begin{array}{c}\text { elementary } \\
\text { secondary } \\
\text { higher }^{2}\end{array}$ & $\begin{array}{l}3(0-4) \\
3(0-4) \\
1(0-4)\end{array}$ & $\begin{array}{c}0.0005^{*} \\
\text { between }^{1} \text { and }{ }^{2} \\
<0.0009\end{array}$ \\
\hline Income & $\begin{array}{l}\text { lowest } \\
\text { average } \\
\text { highest }\end{array}$ & $\begin{array}{l}3(0-4) \\
3(0-4) \\
2(0-4)\end{array}$ & 0.053 \\
\hline Smoking status & $\begin{array}{c}\text { current } \\
\text { former } \\
\text { non-smoker }^{2}\end{array}$ & $\begin{array}{l}3(0-4) \\
3(0-4) \\
3(0-4)\end{array}$ & 0.11 \\
\hline $\mathrm{BMI}$ & $\begin{array}{l}\text { normal weight } \\
\text { overweight } \\
\text { obesity }\end{array}$ & $\begin{array}{l}3(0-4) \\
3(0-4) \\
3(0-4)\end{array}$ & 0.85 \\
\hline Diabetes & $\begin{array}{l}\text { yes } \\
\text { no }\end{array}$ & $\begin{array}{l}3(0-4) \\
3(0-4)\end{array}$ & 0.2 \\
\hline Cardiovascular disease & $\begin{array}{l}\text { yes } \\
\text { no }\end{array}$ & $\begin{array}{l}3(0-4) \\
3(0-4)\end{array}$ & 0.29 \\
\hline Osteoporosis & $\begin{array}{l}\text { yes } \\
\text { no }\end{array}$ & $\begin{array}{l}1(0-4) \\
3(0-4)\end{array}$ & 0.0783 \\
\hline Effectiveness of tooth brushing & $\begin{array}{l}\mathrm{PI}<30 \% \\
\mathrm{PI}>70 \%\end{array}$ & $\begin{array}{l}0(0-4) \\
3(0-4)\end{array}$ & $0.0001^{*}$ \\
\hline $\begin{array}{l}\text { Effectiveness of hygienic procedures } \\
\text { in interdental spaces }\end{array}$ & $\begin{array}{l}\mathrm{API}<25 \% \\
\mathrm{API}>70 \%\end{array}$ & $\begin{array}{l}1(0-4) \\
3(0-4)\end{array}$ & 0.18 \\
\hline Dental appointments & $\begin{array}{l}\text { regularly } \\
\text { irregularly }\end{array}$ & $\begin{array}{l}1.5(0-3) \\
3(0-4)\end{array}$ & $0.0031^{*}$ \\
\hline Brushing teeth & $\begin{array}{l}\text { regularly } \\
\text { irregularly }\end{array}$ & $\begin{array}{l}3(0-4) \\
3(0-4)\end{array}$ & $0.0002^{*}$ \\
\hline Form of dental treatment funding & $\begin{array}{c}\text { NFZ1 }^{1} \\
\text { mixed }^{2} \\
\text { private }^{3}\end{array}$ & $\begin{array}{l}3(0-4) \\
3(0-4) \\
1(0-4)\end{array}$ & $\begin{array}{c}0.0001^{*} \\
\text { between }{ }^{1} \text { and }{ }^{3} \\
<0.0001 \\
\text { between }{ }^{2} \text { and }^{3} \\
0.0019\end{array}$ \\
\hline
\end{tabular}

* statistically significant.

However, in our study the need for prosthetic treatment of edentulism occurred more often in the maxilla (17.1\% vs $10.1 \%)$, and this number was higher in comparison with the needs reported in the West Pomeranian study $-10.5 \%$ and $8.8 \%$, respectively. ${ }^{16}$ In the 2005 Spanish study, such a need occurred in $4.4 \%$ of people in the maxilla and $5 \%$ in the mandible. ${ }^{17}$ This compilation shows considerable needs regarding the prosthetic treatment of young seniors in Poland, significantly higher than those in the richest European countries. Our own analysis showed the same variables related to the smaller needs for prosthetic treatment in the maxilla and the mandible, in line with the WHO classification, and these were as follows: higher education, self-financed dental treatment, effective tooth brushing, regular visits to the dental office, and the correct pattern of daily tooth brushing. In relation to the maxilla, 2 more factors displayed a significant impact on reducing the extent of prosthetic treatment, namely living in a big city and never smoking cigarettes. In the analogous assessment of the inhabitants of the West Pomeranian province, Wilczyński also noted the influence of behavioral factors (correct pattern of daily tooth brushing and regular visits to the dental office) and self-financed dental treatment upon the reduction of prosthetic treatment needs related to the maxilla and mandible, as classified by the WHO; factors such as the highest income, higher education and living in a big city reduced these needs only for the maxilla. ${ }^{16}$

In the assessed population of young Lower Silesian seniors, in relation to European reference points, the needs for dental caries treatment were similarly higher. In a current German national study there were only $21 \%$ of people at the same age with at least 1 carious defect, ${ }^{18}$ or in a Kosovar study, at least 1 carious defect was found in $42.6 \%$ of respondents. ${ }^{19}$ An optimistic aspect of our own study is the high caries treatment index $-81.1 \%$, just slightly lower than the German one $-90.6 \%{ }^{18}$ The DMFT index for the whole group of young seniors in the Lower Silesian region 
was 17.8 and the main component determining its level were extractions due to caries - more than 12 teeth per person on average. The average DT number was 1.05 and was significantly higher in men (1.4 vs 0.72 ), while the average FT number was 4.48. In the 1987 study of Wrocław residents aged 60-80, the DMFT index was 26.5, and its individual components were higher in relation to the current state: $\mathrm{DT}=0.55$ and $\mathrm{MT}=9.9$, while the FT was lower by $0.8 .^{20}$ The differences in men were even more marked (DMFT: 26.2 vs 17.2 , DT: 1.9 vs 1.4 , MT: 22.0 vs 11.4 , and FT: 2.2 vs 44$).{ }^{20}$ These compilations prove that the number of teeth removed due to caries and the average number of dental fillings declined significantly over 30 years, which should be evaluated as positive. In the available contemporary Polish literature, only 2 regional references were found. The first is the DMFT index 16.31 (DT $=2.95$, $\mathrm{MT}=10.91$ and FT $=2.45)$ in the study of 106 men aged 65-74 from Białystok. ${ }^{21}$ A comparison of the caries indices in both studies shows a similar frequency of teeth removal due to this reason, as well as a lower number of teeth with active caries and almost 2 filled teeth more in the study for Wrocław. The other reference point concerns people aged 65-74 from the West Pomeranian province, where the DMFT index was calculated depending on the type of dental treatment financing, and for those treated only in NFZ facilities and those treated in private facilities, the variables were, respectively, as follows: DT: 0.99 and 0.9 (in our own research: 1.41 and 0.87); MT: 18.14 and 9.73 (in our own research: 15.59 and 9.36); and FT: 3.74 and 9.43 (in our own research: 2.31 and 6.26). ${ }^{16}$ This comparison reveals large differences between the two provinces, especially in the number of teeth removed for cariological reasons, the number of dental fillings and better care within NFZ facilities in this regard in the West Pomeranian province.

The periodontal care need index that amounts up to $35 \%$ in the examined population of young Lower Silesian seniors should be assessed as high. No such criterion of qualification for specialist periodontal treatment had been found in the available literature. However, this choice was driven by the desire to avoid measuring the position of the attachment in such a qualification, which at this age, regardless of periodontopathies, is moving apically, ${ }^{22}$ which obviously may lead to an overestimation of therapeutic needs. In the 5-year cohort study, the most important risk factors for the progression of periodontitis in the 60-81 age group were identified - current nicotinism, elementary or secondary education, being single or divorced, and diabetes. ${ }^{23}$ Periodontological treatment of the elderly has its own limitations, which include general health conditions, physical handicaps, as well as lower predictability of the healing process after surgical procedures.

The percentage of indications regarding the treatment of oral mucosal diseases $(35.4 \%)$ was quite similar to the periodontal needs. A foreign regional study, in which the prevalence of oral mucosal lesions requiring treatment in subjects at the corresponding age was the closest to our observations, i.e., 36\%, was carried out in a group of 537 Hong Kong residents. ${ }^{24}$ Also in this group, the most frequently diagnosed diseases were prosthetic stomatitis, leukokeratosis, recurrent aphthous stomatitis, and angular cheilitis. ${ }^{24}$ However, the frequency of occurrence of pathological oral mucosal lesions requiring treatment in the elderly is more diverse. In more recent observations, this percentage was $59.5 \%$ in the regional study in Valparaiso in Chile (the most common changes were prosthetic stomatitis, traumatic ulcer, fibroma, and atrophic inflammation of the tongue), ${ }^{25}$ and $11.8 \%$ in the last national German study (the two most common clinical diagnoses were prosthetic stomatitis and leukoplakia). ${ }^{26}$ In our own study, as high as $9.6 \%$ percentage of people with oral pre-cancerous and cancerous lesions is also noticeable, which reinforces the message concerning the requirement of oncological vigilance.

In $29.2 \%$ of the surveyed young Lower Silesian seniors, extremely poor oral hygiene was demonstrated in the form of over $70 \%$ average value of the index of teeth brushing effectiveness and interdental space cleaning. The adopted threshold is not very high; not reaching it indicates a practical absence of hygienic procedures in the oral cavity or their total ineffectiveness. Changing longterm habits regarding pro-health behaviors has a fairly bad prognosis - it is very difficult and requires constant re-education.

In Table 1, for each gerodontological treatment need there were given 3 subgroups of persons for whom they were the highest. In the case of the tobacco addiction syndrome, the distinguished subgroup of people placed itself among those 3 with the highest needs for each type of gerodontological treatment, and for periodontal treatment and oral mucosal diseases, this was the top subgroup with the highest needs. This shows very clearly the impact of nicotinism on the holistically perceived dentistry. Fortunately, it is a modifiable risk factor, which makes it possible to significantly reduce the need for gerodontological treatment once this addiction is dropped. It is absolutely necessary to conduct minimal antismoking interventions during every patient's visit to the dental office. The second modifiable risk factor forming subgroups with the highests need for gerodontological treatment is the incorrect pattern of daily tooth brushing. While nicotinism is an addiction, irregular brushing is only a bad habit and as such it does not involve any special financial consequences while being eradicated, but still it requires cooperation on the part of the patient. Focusing on preventive programs addressed to younger groups of Poles only in the area of these 2 risk factors should significantly reduce the needs for gerodontological treatment of young seniors in the future. 
Our own research had a number of limitations. First of all, it is the low response rate of the elderly, which determines its low representativeness. The reported $24.2 \%$ response rate was higher than the response rates in other Polish regional dental examinations of young seniors - $7.2 \%$ in Białystok ${ }^{27}$ and $11.8 \%$ in the West Pomeranian province. ${ }^{16}$ However, these values are low compared to foreign ones; for example, in the last regional German cohort study, Study of Health in Pomerania (SHIP), carried out in the years 2008-2012, the response rate was 50.1\%, ${ }^{23}$ and in the Italian regional survey among the inhabitants of Turin conducted in 2009-2010, it was 50.12\%. ${ }^{28}$ It is not known if people participating in epidemiological research in Poland represent larger or smaller needs in the area of gerodontological treatment. Secondly, it is advisable to conduct separate observations for root caries. Due to the inability to obtain a review radiographic image, the needs of endodontic and surgical treatment were not determined.

\section{Conclusions}

This is the first attempt in Poland to assess the majority of gerodontological treatment needs in a randomized regional cross-sectional study. It demonstrates high needs for the prosthetic, cariological and periodontal treatment. Such national studies are necessary, because on their bases we can more pragmatically create the scope of dental procedures financed by the public healthcare service and develop adequately focused preventive campaigns for younger groups.

\section{ORCID iDs}

Beata Głowacka (1) https://orcid.org/0000-0003-0675-3719

Tomasz Konopka (1) https://orcid.org/0000-0002-8808-2893

\section{References}

1. Nadig RR, Usha G, Kumar V, Rao R, Bugalia A. Geriatric restorative care - the need, the demand and the challenges. J Conserv Dent. 2011;14(3):208-214.

2. Wysokińska-MiszczukJ,SieczkarekJ.Gerostomatology-theoretical justifications and practical usefulness in medical sciences [in Polish]. Twój Przeg/ Stomatol. 2002;1:26-27.

3. Piotrowska D, Pędziński B, Szpak A. Financing dental services from public and non-public sources in Poland [in Polish]. Hygeia Public Health. 2016;51(1):12-17.

4. Health care in households in 2013. GUS, Warszawa 2014 [in Polish]. Available on the website: http://stat.gov.pl/obszary-tematyczne/ zdrowie/zdrowie/ochrona-zdrowia-w-gospodarstwachdomowych-w-2013-r-,2,5.html. Accessed on March 28, 2018.

5. Information on the situation of elderly people in Poland for 2016. MRPiPS, Warszawa 2017 [in Polish]. Available on the website: http://senior.gov.pl/materialy_i_badania/pokaz/300. Accessed on March 28, 2018.

6. White BA. Factors influencing demand for dental services: Population, demographics, disease, insurance. J Dent Educ. 2012;76(8):8996-9007.

7. Głowacka B, Konopka T. Prevalence of oral mucosal lesions among young seniors in the Wrocław region. Dent Med Probl. 2018;55(4):405-410.
8. World Health Organization. Guidelines for the Conduct of Tobacco Smoking Surveys for the General Population. Geneva, Switzerland: WHO; 1983:7-8.

9. O'Leary TJ, Drake RB, Naylor JE. The plaque control record. J. Periodontol. 1972;43(1):38.

10. Lange DE, Plagmann HC, Eenboom A, Promesberger A. Clinical methods for the objective evaluation of oral hygiene [in German]. Deutsch Zahnärztl Zeitschr. 1977;32(1):44-47.

11. Dhingara $\mathrm{K}$, Vandana KL. Indices for measuring periodontitis: A literature review. Int Dent J. 2011;61(2):76-84.

12. World Health Organization. Oral Health Surveys: Basic Methods. $4^{\text {th }}$ ed. Geneva, Switzerland: WHO; 1997.

13. World Health Organization. Oral Health Surveys: Basic Methods. $5^{\text {th }}$ ed. Geneva, Switzerland: WHO; 2013.

14. Wierzbicka M, Szatko F, Zawadziński M, et al. All-country Monitoring of Oral Health and Its Conditions. Poland 2003 [in Polish]. Warszawa, Poland: Ministry of Health and Social Care, Institute of Stomatology at the Medical University in Warsaw, Department of Hygiene and Epidemiology at the Medical University of Lodz; 2003:18-33.

15. Landry RG, Jean M. Periodontal Screening and Recording (PSR) Index: Precursors, utility and limitations in a clinical setting. Int Dent J. 2002;52:35-40.

16. Wilczyński Ł. Prosthetic status and needs of prosthetic treatment of missing teeth in patients aged 65-74 in the West Pomeranian province [in Polish]. PhD thesis, PUM in Szczecin, 2016.

17. Bravo-Pérez M, Casals-Peidró E, Cortés-Martinicorena FJ, Llodra-Calvo JC. Survey on oral health in Spain 2005 [in Spanish]. RCOE. 2006;11(4):409-456.

18. Schiffner U. Assessment of oral health status among young seniors (aged 65 to 74). Dental caries and erosion [in German]. In: Jordan R, Micheelis W, eds. Fünfte Deutsche Mundgesundheitsstudie (DMS V). Köln, Germany: Deutscher Zahnärzte Verlag DÄV; 2016:363-395.

19. Kamberi B, Koçani F, Begzati $A$, et al. Prevalence of dental caries in Kosovar adult population. Int Dent J. 2016;2016:4290291.

20. Kaczmarek U, Potoczek S, Malepszy A, et al. Dentiton status of women and men in Wrocław population [in Polish]. Wrocł Stomatol. 1987:165-171.

21. Szpak A, Stokowska W, Gołębiewska E. Dentition status and treatment needs of 65-74-year-old men living in Bialystok [in Polish]. Probl Hig Epidemiol. 2012(2);93:97-104.

22. Person GR. Dental geriatrics and periodontitis. Periodontol 2000. 2017;74(1):102-115.

23. Gätke D, Holtfreter B, Biffar R, Kocher T. Five-year change of periodontal diseases in the Study of Health in Pomerania (SHIP). J Clin Periodontol. 2012;39(4):357-367.

24. Corbet EF, Holmgren CJ, Phillipsen HP. Oral mucosal lesions in 65-74-year-old Hong Kong Chinese. Community Dent Oral Epidemiol. 1994;22(5 Pt 2):392-395.

25. Cueto A, Martinez R, Niklander S, Deichler J, Barraza A, Esguep A. Prevalence of oral mucosal lesions in an elderly population of the city of Valparaiso, Chile. Gerodontology. 2013;30(3):201-206.

26. Hertrampf K. Disease and medical care prevalence in young seniors (65-74 years of age). Oral mucosa findings [in German]. In: Jordan AR, Micheelis W, eds. Fünfte Deutsche Mundgesundheitsstudie (DMS V). Koln, Germany: Deutscher Zahnärzte Verlag DÄV; 2016:359-362.

27. Sulewska M, Pietruski J, Sulima E, et al. Periodontal status of Bialystok citizens aged 65-74 year: A pilot study. Dent Med Probl. 2017;54(2):173-178.

28. Aimetti M, Perotto S, Castiglione A, Mariani GM, Ferrarotti F, Romano F. Prevalence of periodontitis in an adult population from an urban area in North Italy: Findings from a cross-sectional population-based epidemiological survey. J Clin Periodontol. 2015;42(7):622-631. 